\title{
TRPV1 activation impedes foam cell formation by inducing autophagy in oxLDL-treated vascular smooth muscle cells
}

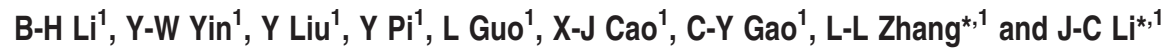

Vascular smooth muscle cells (VSMCs) are an important origin of foam cells besides macrophages. The mechanisms underlying VSMC foam cell formation are relatively little known. Activation of transient receptor potential vanilloid subfamily 1 (TRPV1) and autophagy have a potential role in regulating foam cell formation. Our study demonstrated that autophagy protected against foam cell formation in oxidized low-density lipoprotein (oxLDL)-treated VSMCs; activation of TRPV1 by capsaicin rescued the autophagy impaired by oxLDL and activated autophagy-lysosome pathway in VSMCs; activation of TRPV1 by capsaicin impeded foam cell formation of VSMCs through autophagy induction; activation of TRPV1 by capsaicin induced autophagy through AMP-activated protein kinase (AMPK) signaling pathway. This study provides evidence that autophagy plays an important role in VSMC foam cell formation and highlights TRPV1 as a promising therapeutic target in atherosclerosis.

Cell Death and Disease (2014) 5, e1182; doi:10.1038/cddis.2014.146; published online 17 April 2014

Subject Category: Experimental Medicine

Atherosclerosis is the leading cause of cardio- and cerebrovascular events. The key early event in atherosclerosis is the foam cell formation that accumulates cytoplasmic droplets of cholesterol esters and triglycerides. Foam cells have traditionally been regarded as being derived from macrophages; however, it is reported that vascular smooth muscle cells (VSMCs) also give rise to a significant number of foam cells. ${ }^{1-3}$ In advanced atherosclerosis lesions, only $30 \%$ of foam cells displayed macrophage markers, whereas $45 \%$ have a VSMC phenotype. ${ }^{4}$ However, compared with macrophages, the mechanisms underlying VSMC foam cell formation are relatively little known. Fully elucidating these mechanisms would be helpful for the prevention and treatment of atherosclerosis.

Macroautophagy, which we refer to as autophagy hereafter, is a process of 'self-eating' that acts as a major survival mechanism by degrading and recycling organelles and portions in cytosol. ${ }^{5}$ The autophagic process involves the formation of double-membrane autophagosomes that engulf cytoplasmic materials and fuse with lysosomes, and thus deliver the autophagic body into the lysosomal lumen for degradation. ${ }^{5,6}$ Recently, autophagy has been shown to participate in glucose, protein and lipid metabolism. ${ }^{7-9}$ In macrophage foam cell, autophagy regulates cholesterol efflux via lysosomal acid lipase. Lipid droplets are delivered to lysosomes and then hydrolyzed to generate free cholesterol mainly for ATP-binding cassette transporter A1 (ABCA1)dependent efflux. ${ }^{10}$ Activation of autophagy can decrease, whereas inhibition of autophagy can increase, the intracellular accumulation of total cholesterol and cholesterol esters. ${ }^{11}$ However, the potential role of autophagy in the VSMC foam cell formation has been rarely reported.

Transient receptor potential vanilloid subfamily 1 (TRPV1), a nonselective cation channel that is activated by capsaicin, has a protective effect against cardiovascular and cerebrovascular diseases. ${ }^{12-17}$ TRPV1 expresses in VSMC and is found to reduce the lipid accumulation in cultured cells via increasing cholesterol efflux and reducing lipid uptake. ${ }^{13}$ Most recently, activation of TRPV1 by capsaicin has been reported to induce autophagy in hepatocytes and mouse thymocytes. ${ }^{12,18}$ Herein, the present study was designed to investigate potential role of autophagy in VSMC foam cell formation, and the potential effect of TRPV1 on autophagy in VSMCs challenged with oxidized low-density lipoprotein (oxLDL).

\section{Results}

Autophagy protects against foam cell formation in oxLDL-treated VSMCs. To address the role of autophagy in VSMC foam cell formation, first, we detected the changes of autophagy in oxLDL-treated VSMCs. As shown in Figures $1 a$ and b, exposure to oxLDL decreased the LC3II/LC3I ratio and beclin-1 level in a time-dependent manner in VSMCs, with an obvious effect at $24 \mathrm{~h}$ post oxLDL challenge. Moreover, a marked increase of p62 was observed $24 \mathrm{~h}$ after oxLDL exposure (Figure 1c). Next, we examined the effect of autophagy on foam cell formation in oxLDL-treated

\footnotetext{
${ }^{1}$ Department of Neurology, Institute of Surgery Research, Daping Hospital, Third Military Medical University, Chongqing, People's Republic of China

*Corresponding author: L-L Zhang or J-C Li, Department of Neurology, Institute of Surgery Research, Daping Hospital, Third Military Medical University, 10 Changjiang Branch Road, Yuzhong District, Chongqing 400042, People's Republic of China. Tel/Fax: +86 23 68757842; E-mail: zll197312@ @otmail.com (L-LZ) or Tel/Fax: +86 23 68757841; E-mail: lijingcheng11@aliyun.com (J-CL)

Keywords: AMP-activated protein kinase; autophagy; foam cell; transient receptor potential vanilloid subfamily 1; vascular smooth muscle cell

Abbreviations: AMPK, AMP-activated protein kinase; Atg7, autophagy-related gene 7; 3-MA, 3-methyladenine; LAMP-1, lysosomal-associated membrane protein 1; oxLDL, oxidized low-density lipoprotein; TRPV1, transient receptor potential vanilloid subfamily 1; VSMC, vascular smooth muscle cell

Received 02.10.13; revised 25.2.13; accepted 04.3.14; Edited by GM Fimia
} 

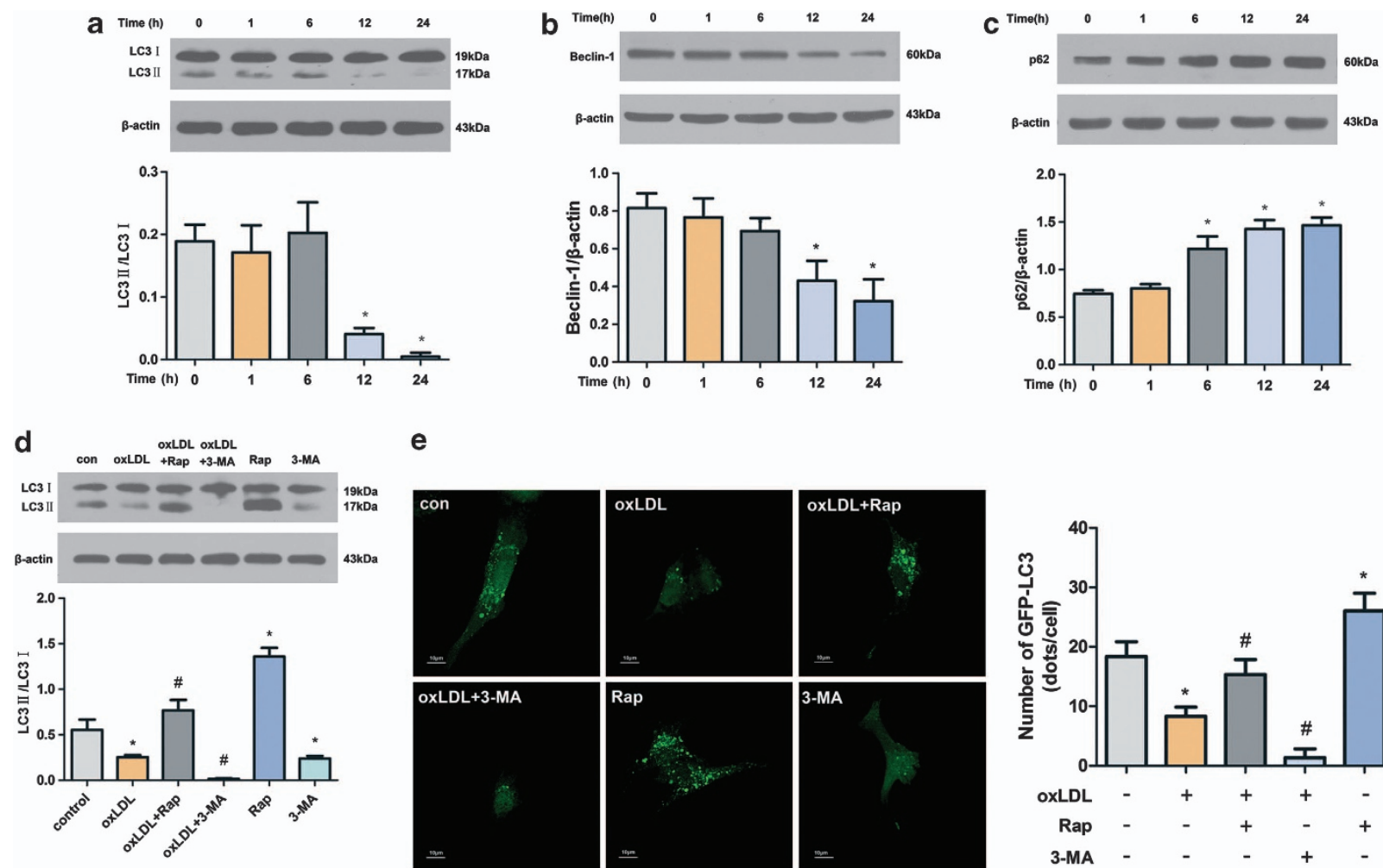

e
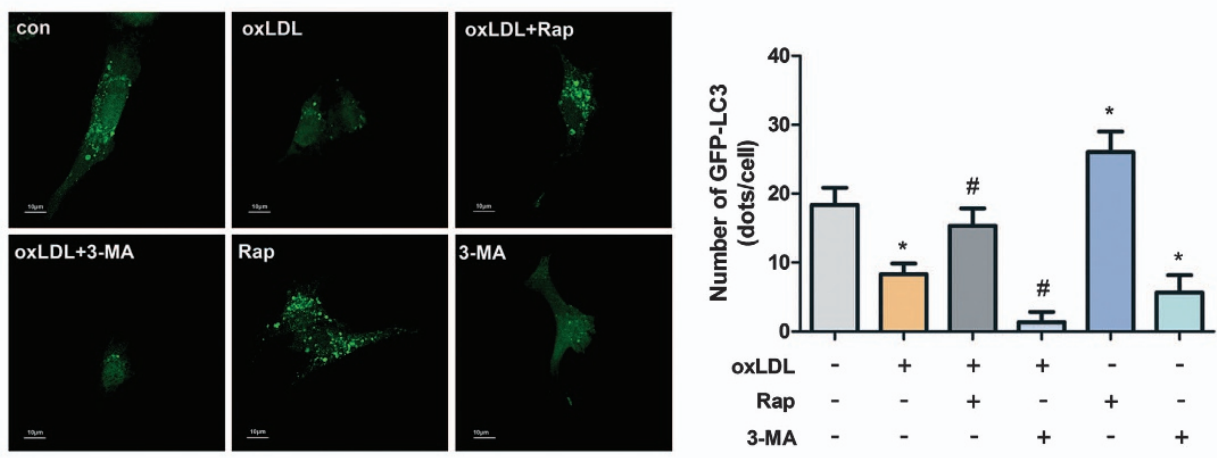

f

g
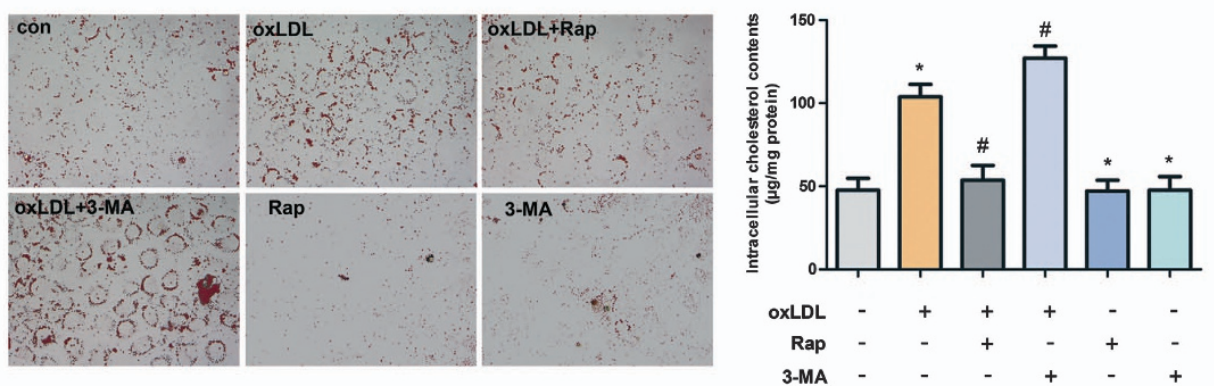

Figure 1 Autophagy protects against foam cell formation in oxLDL-treated VSMCs. (a-c) Primary VSMCs from wild-type (WT) mice were incubated with oxLDL (80 $\mu \mathrm{g} / \mathrm{ml})$ for different times $(0,1,6,12$ or $24 \mathrm{~h})$. LC3II/LC3I ratio and beclin-1 level were decreased and the level of p62 was increased in a time-dependent manner, with an obvious effect at $24 \mathrm{~h}$ post oxLDL challenge; ${ }^{*} P<0.05$ versus $0 \mathrm{~h}$. (d-g) Primary VSMCs from WT mice were treated with either the vehicle solution (con) or oxLDL ( $80 \mu \mathrm{g} / \mathrm{ml}$ ) in the absence or presence of rapamycin (Rap; $10 \mathrm{nM}$ ) and 3-methyladenine (3-MA; $5 \mathrm{mM}$ ) as indicated for $24 \mathrm{~h}$. Rap rescued, whereas 3-MA exacerbated, the impaired autophagy in oxLDL-treated VSMCs, manifested by the changes of LC3-II/LC3-I ratio (d) and GFP-labeled autophagosomes (e). Rap reduced whereas 3-MA increased lipid droplet accumulation and intracellular cholesterol content (f and $\mathbf{g}$ ); ${ }^{*} P<0.05$ versus con; ${ }^{\#} P<0.05$ versus oxLDL alone. Results were presented as mean \pm S.D. (error bars) of three independent experiments

VSMCs. Rapamycin (Rap, an inhibitor of mTOR) and 3-methyladenine (3-MA, an inhibitor of autophagy) were respectively used to induce and inhibit autophagy in VSMCs. As expected, Rap rescued, whereas 3-MA exacerbated, the impaired autophagy in oxLDL-treated VSMCs, manifested by the changes of LC3-II/LC3-I ratio (Figure 1d) and GFP-labeled autophagosomes (Figure 1e). Consistently, both Oil Red $\mathrm{O}$ staining and total cholesterol quantification showed that Rap inhibited the oxLDL-induced foam cell formation, whereas 3-MA exerted the opposite effect (Figures $1 f$ and g). Together, these results show that autophagy protects against foam cell formation in oxLDLtreated VSMCs.
A previous study showed that high oxLDL concentration $(>60 \mu \mathrm{g} / \mathrm{ml})$ induced VSMC apoptosis. ${ }^{19}$ In our study, we also performed apoptosis assays by double staining with Annexin V-FITC/propidium iodide (PI) and detecting caspase 3 activity in cells treated with oxLDL or nLDL. The data indicated early apoptosis induced by $80 \mu \mathrm{g} / \mathrm{ml}$ oxLDL. However, late apoptosis and necrosis were not induced (Supplementary Figure 1).

Activation of TRPV1 by capsaicin rescues the autophagy impaired by oxLDL in VSMCs. The induction of capsaicin on autophagy was previously reported in malignant breast epithelial cells and mouse thymocytes. ${ }^{12,20}$ The present 
study showed that this induction also exists in VSMCs. As shown in Figure 2a, the impaired autophagy by oxLDL was markedly rescued by capsaicin in a dose-dependent manner, with the maximal effect at $1 \mu \mathrm{M}$, demonstrated by the increased LC3II/LC3I ratio and beclin-1 level. Capsaicin $(1 \mu \mathrm{M})$ significantly increased the LC3II/LC3I ratio, beclin-1 level and GFP-labeled autophagosomes in oxLDL-stimulated
VSMCs from wild-type (WT) mice but not TRPV1 knockout $\left(\mathrm{TRPV}^{-{ }^{-1}}{ }^{-}\right.$) mice (Figures $2 \mathrm{~b}-\mathrm{d}$ ). Furthermore, the promotion of capsaicin on LC3II/LC3I ratio and beclin-1 level were reversed by TRPV1 antagonist 5'-iodo-resiniferatoxin (iRTX), but it was not the case in VSMCs from TRPV1 ${ }^{-1-}$ mice. These data suggest that activation of TRPV1 by capsaicin rescues the impaired autophagy in oxLDL-treated VSMCs.
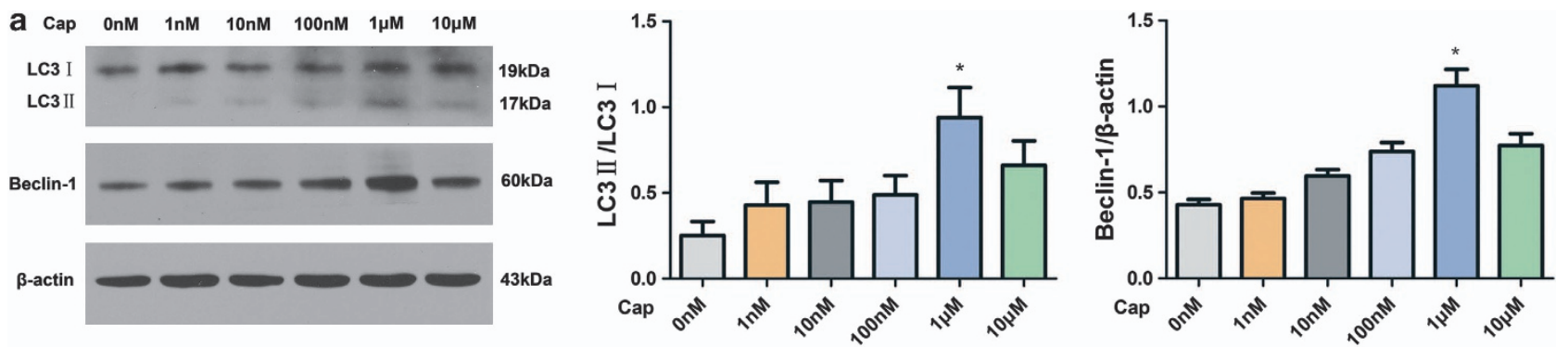

b
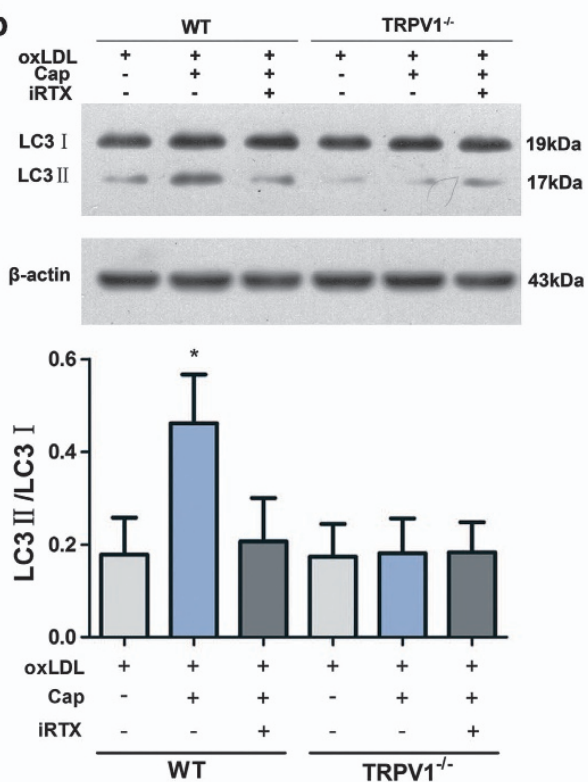

C
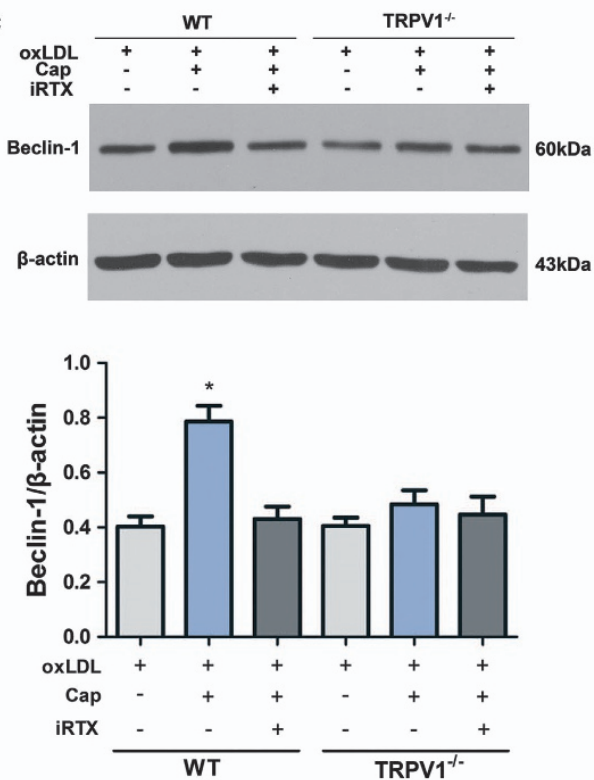

d

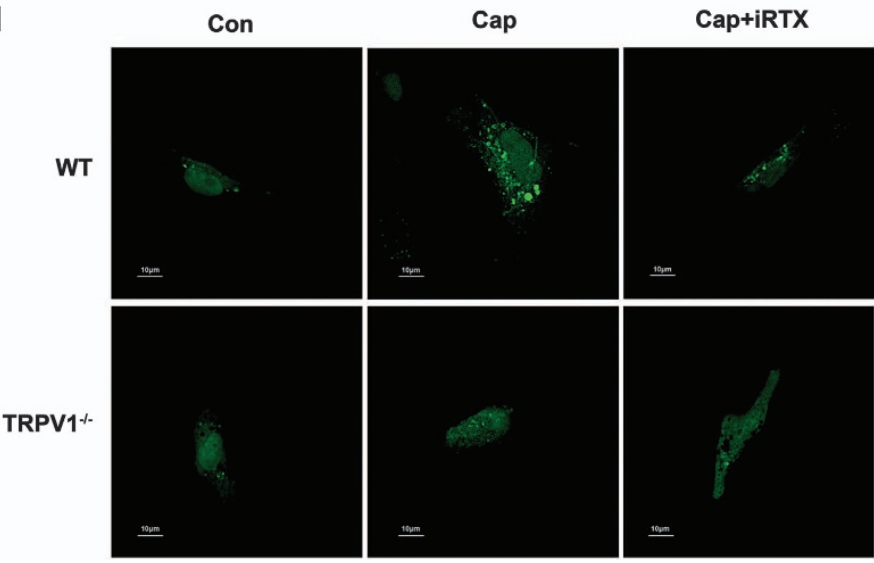

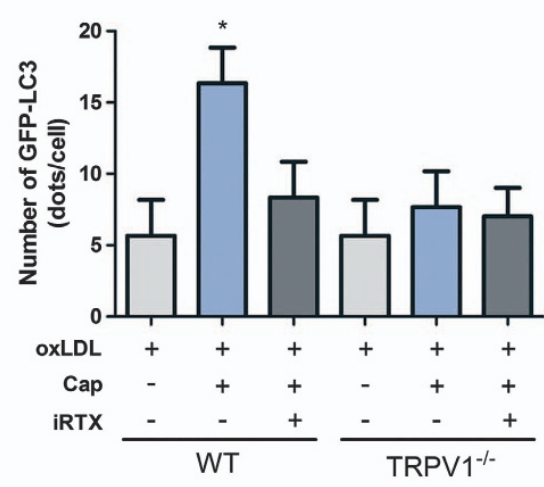

Figure 2 Activation of TRPV1 by capsaicin rescues the autophagy impaired by oxLDL in VSMCs. (a) Primary VSMCs from wild-type (WT) mice were incubated with oxLDL with different amounts of capsaicin (Cap). Cap dose-dependently increased the LC3II/LC3I ratio and beclin-1 level with the maximal effect at $1 \mu \mathrm{M}$; ${ }^{*} P<0.05$ versus control $(0 \mathrm{nM})$. (b-d) Primary VSMCs from WT and TRPV1 ${ }^{-1-}$ mice were treated with oxLDL in the absence (con) and presence of Cap $(1 \mu \mathrm{M})$ or combined with iRTX (1 $\left.\mu \mathrm{M}\right)$. Cap significantly increased the LC3II/LC3I ratio (b), beclin-1 level (c) and GFP-tagged LC3 dots (d) in VSMCs from WT mice that was reversed by TRPV1 antagonist iRTX, but it was not the case in VSMCs from TRPV1 ${ }^{-I-}$ mice; ${ }^{*} P<0.05$ versus others. Results were presented as mean \pm S.D. (error bars) of three independent experiments 
Activation of TRPV1 by capsaicin activates autophagylysosome pathway. Lysosomes and autophagolysosomes are crucial particles in autophagy-mediated degradation of macromolecules. ${ }^{6}$ Therefore, the marker protein of lysosomes, lysosomal-associated membrane protein 1 (LAMP-1), was detected to identify whether activation of TRPV1 by capsaicin activates autophagy-lysosome pathway in oxLDL-treated VSMCs. ${ }^{10}$ It was shown that capsaicin significantly increased the expression of LAMP-1 (Figure 3a) and the number of lysosomes (Figure $3 b$ ) in oxLDLstimulated VSMCs from WT mice that was counteracted by TRPV1 inhibitor iRTX. In oxLDL-stimulated VSMCs from TRPV $1^{-1-}$ mice, no detectable change in LAMP-1 expression was found. Next, we further investigated the effect of activation of TRPV1 by capsaicin on autophagy-lysosome pathway in vivo. Addition of capsaicin significantly increased the expression of LAMP-1 in the area of smooth muscle cells. In contrast, capsaicin exerted no effect on the expression of LAMP-1 in TRPV $1^{-1-}$ mice (Figure 3c).

Activation of TRPV1 by capsaicin inhibits VSMC foam cell formation through induction of autophagy. To investigate whether activation of TRPV1 by capsaicin inhibits VSMC foam cell formation through autophagy induction, we used autophagy-related gene 7 (Atg7) small interfering RNA (siRNA) to knock down Atg7, a key autophagy-related gene. In VSMCs transfected with con siRNA, capsaicin significantly induced autophagy manifested by increased Atg7 (Figure 4a) and LC3-II/LC3-I ratio (Figure 4b), and inhibited oxLDL-induced foam cell formation manifested by decreased lipid droplet accumulation (Figure 4c) and total cholesterol level (Figure 4d). On the contrary, in Atg7 knockdown VSMCs, capsaicin failed to impede the oxLDLinduced lipid accumulation and cholesterol increase, accompanied by unchanged LC3-II/LC3-I ratio. These data suggest that activation of TRPV1 by capsaicin inhibits foam cell formation through induction of autophagy in oxLDLtreated VSMCs. Activation of TRPV1 by capsaicin induces autophagy
through AMPK signaling pathway. To further investigate
the potential mechanisms of TRPV1 in inducing autophagy in
VSMCs, we analyzed the activation status of AMP-activated
protein kinase (AMPK) signaling. As shown in Figure $5 a$,
capsaicin significantly increased p-AMPK (Thr-172) expres-
sion that was reversed by iRTX in VSMCs from WT mice.
In contrast, capsaicin exerted no effect on the expression of
p-AMPK in VSMCs from TRPV1 ${ }^{-/}$mice. Furthermore, we
evaluated the involvement of AMPK activation in TRPV1-
induced autophagy by using the AMPK inhibitor compound C.
As shown in Figure $5 \mathrm{~b}$, compound C significantly inhibited
the TRPV1-activated AMPK. Moreover, increase in Atg7 level (Figure 5c) and LC3-II/LC3-I ratio (Figure 5d) were significantly attenuated by addition of compound $\mathrm{C}$.

\section{Discussion}

Being an important origin of foam cells, VSMCs have gained increasing attention. The mechanisms underlying VSMC foam cell formation have become an important area of ongoing investigation. ${ }^{21}$ Our study demonstrated that autophagy protected against foam cell formation in oxLDL-treated VSMCs; activation of TRPV1 by capsaicin rescued the autophagy impaired by oxLDL and activated autophagylysosome pathway in VSMCs; activation of TRPV1 by capsaicin impeded VSMC foam cell formation through autophagy induction; activation of TRPV1 by capsaicin induced autophagy through AMPK signaling pathway.

Autophagy has been implicated in various biological processes, including aging, development, tumorigenesis, cell death and differentiation by breaking down macromolecules and aged/damaged cellular organelles. ${ }^{5,22-24}$ Autophagy has also been found to play a key role in the development of diseases, including cancer, ${ }^{25}$ neurodegenerative disorders, ${ }^{26}$ inflammatory bowel disease ${ }^{27}$ and atherosclerosis. ${ }^{28,29}$ Reportedly, autophagy exerts both protective and deleterious effects on atherosclerosis. ${ }^{28,29}$ A recent study showed that activation of autophagy reduced levels of total cholesterol and cholesterol esters in macrophages exposed to LDL cholesterol, and thus inhibited the foam cell formation. ${ }^{11}$ However, the potential role of autophagy in VSMC foam cell formation is poorly understood.

In the present study, we used oxLDL, a well-known atherogenic factor, ${ }^{30,31}$ to induce VSMC foam cell formation. We first detected the effect of oxLDL on autophagy. The data showed that autophagy in VSMCs was significantly inhibited by oxLDL, with decreased LC3II/LC3I ratio and beclin-1 level. The well-established autophagy-negative regulator, mTOR, ${ }^{32}$ may mediate the effect of oxLDL on autophagy. It was reported that oxLDL was capable of activating the PI3K/Akt/ mTOR pathway in VSMCs. ${ }^{33}$ In addition, oxLDL has also been shown to upregulate p38 mitogen-activated protein kinase ${ }^{11}$ that can activate mTOR $^{34}$ or inhibit autophagy directly. ${ }^{11}$ Therefore, we speculated that it was through the mTOR signaling, at least in part, that oxLDL inhibited autophagy. Further studies are warranted to elucidate detailed cellular and molecular mechanisms for this phenomenon.

Next, we explored the role of autophagy in VSMC foam cell formation by using Rap (an inhibitor of mTOR) to induce autophagy and 3-MA (an inhibitor of autophagy) to inhibit autophagy. Our results showed that activation of autophagy reduced Oil Red O-positive staining and total cholesterol level in VSMCs exposed to oxLDL, whereas inhibition of autophagy exerted the opposite effect. These data provide evidence that

\footnotetext{
Figure 3 Activation of TRPV1 by capsaicin activates autophagy-lysosome pathway in oxLDL-loaded VSMCs. (a and $\mathbf{b}$ ) Primary VSMCs from wild-type (WT) and $\mathrm{TRPV}^{-1-}$ mice were treated with oxLDL in the absence (con) and presence of Cap $(1 \mu \mathrm{M})$ or combined with $\mathrm{RTX}(1 \mu \mathrm{M})$ for $24 \mathrm{~h}$. Cap significantly increased the expression of LAMP-1 (a) and the number of lysosomes (b) in oxLDL-stimulated VSMCs from WT mice that was counteracted by TRPV1 inhibitor iRTX. In oxLDL-stimulated VSMCs from TRPV1 ${ }^{-1-}$ mice, no detectable change in LAMP-1 expression was found; ${ }^{*} P<0.05$ versus others. (c) Representative images of aorta detected by immunofluorescence are shown. Addition of Cap significantly increased the expression of LAMP-1 in the area of smooth muscle cells. In contrast, Cap exerted no effect on the expression of LAMP-1 in TRPV1 ${ }^{-1-}$ mice. Results were presented as mean \pm S.D. (error bars) of three independent experiments
} 
a

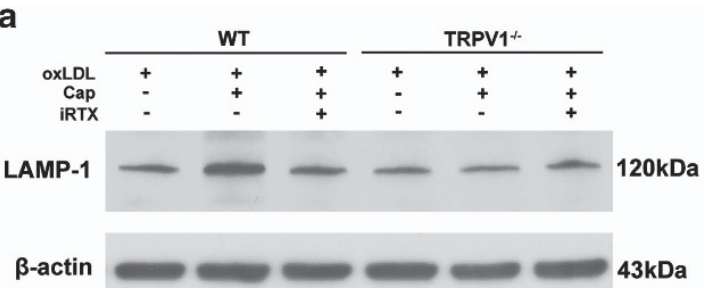

b

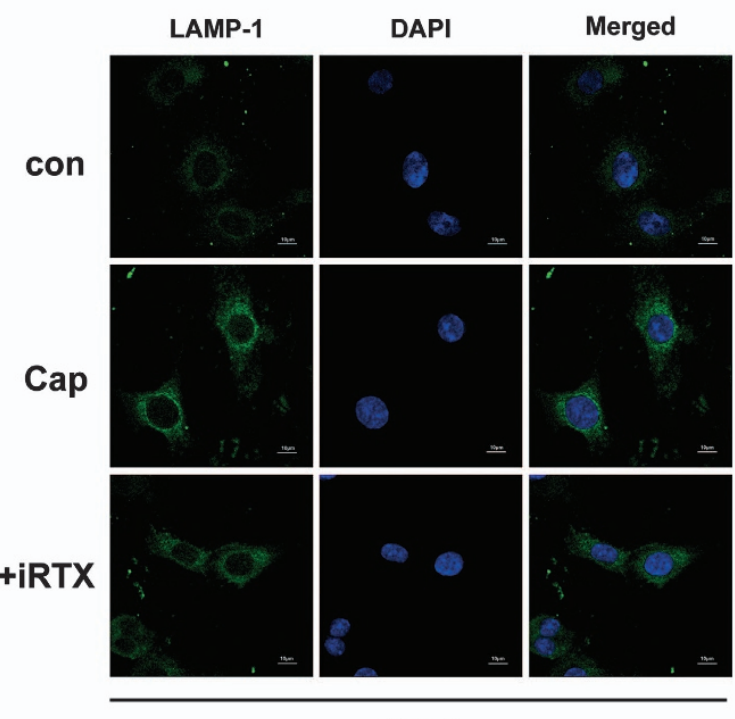

WT

c

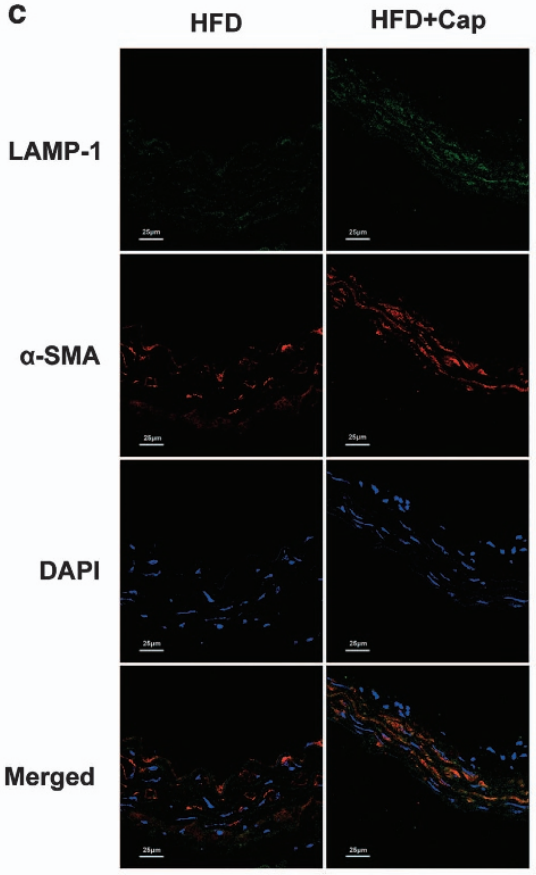

WT
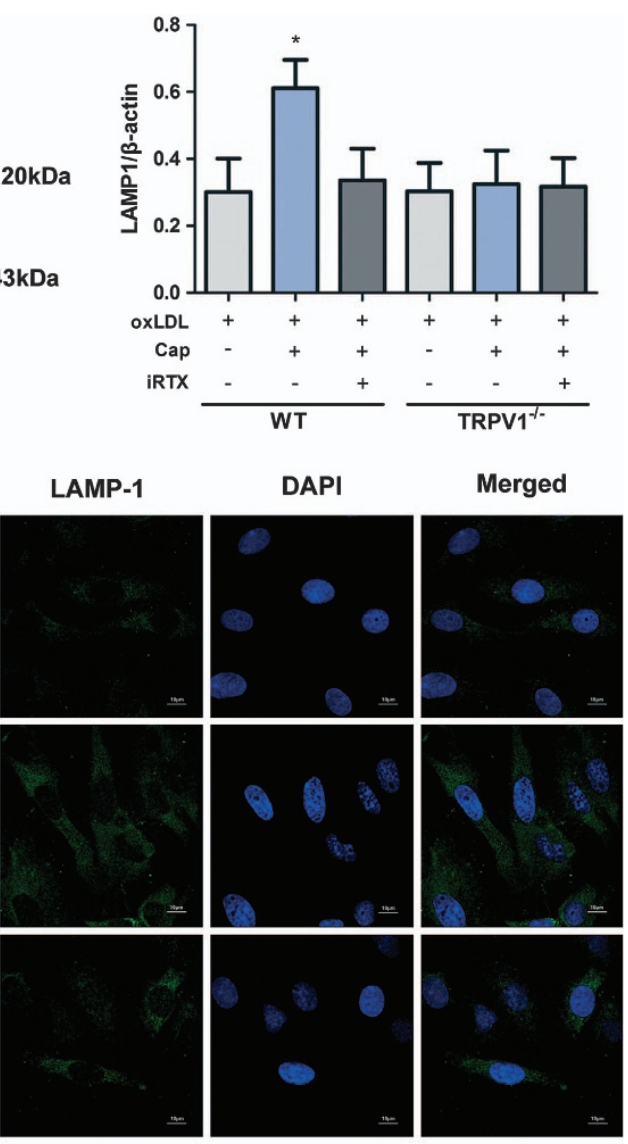

TRPV1

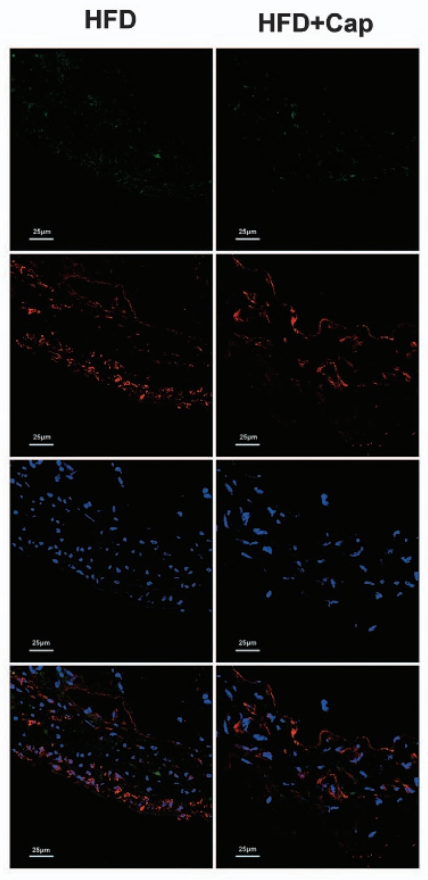

TRPV1 ${ }^{-/-}$ 
a
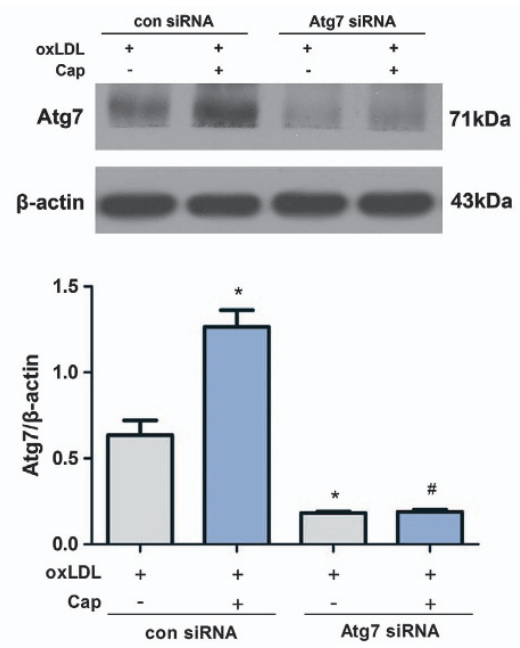

c

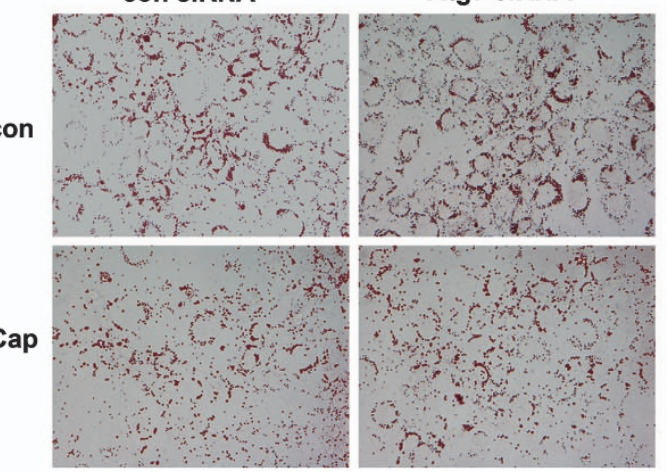

b
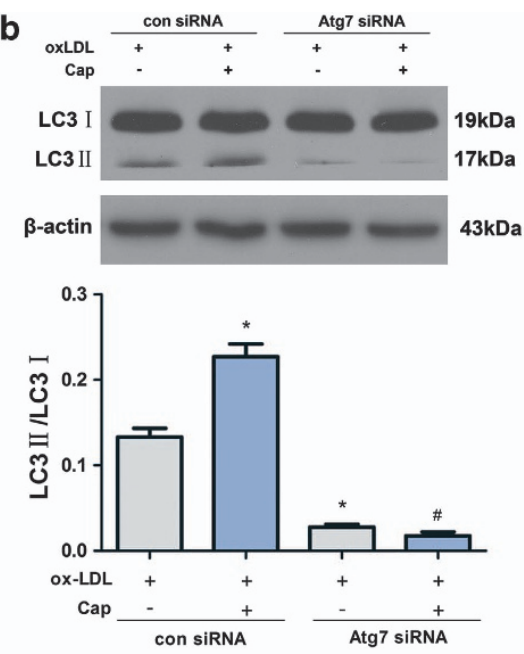

d

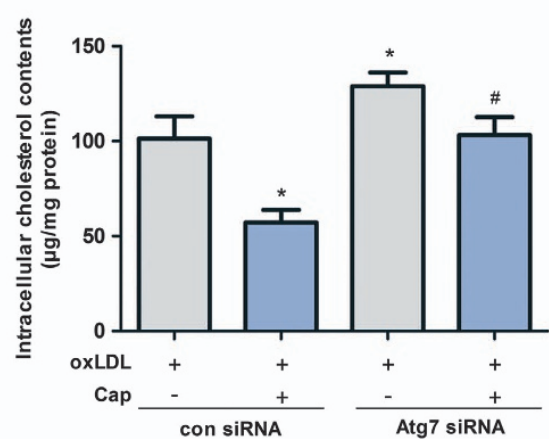

Figure 4 Activation of TRPV1 by capsaicin inhibits VSMC foam cell formation through autophagy induction. (a-d) Primary VSMCs from wild-type (WT) mice were transfected with con siRNA or Agt7 siRNA and then treated with oxLDL in the absence or presence of Cap. Cap significantly increased the level of Atg7 and the LC3-II/LC3-I ratio, and decreased lipid droplet accumulation and total cholesterol levels in VSMCs transfected with con siRNA, whereas no alteration was shown in VSMCs transfected with Atg7 siRNA; ${ }^{*} P<0.05$ versus con siRNA + oxLDL; ${ }^{P} P<0.05$ versus con siRNA + oxLDL + Cap. Results were presented as mean \pm S.D. (error bars) of three independent experiments

autophagy inhibits oxLDL-induced VSMC foam cell formation, and suggest autophagy as a novel protective mechanism for VSMCs loaded with oxLDL.

TRPV1 channel is activated by the specific agonist, capsaicin, that is the major pungent ingredient in hot peppers. ${ }^{14,35}$ TRPV1 channel is highly expressed in sensory neurons but has also been detected in blood vessels. ${ }^{36}$ Previous studies indicated that activation of TRPV1 by capsaicin could affect lipid metabolism. ${ }^{15,17}$ In VSMCs treated with oxLDL, TRPV1 activation increased ABCA1 expression and reduced low-density lipoprotein-related protein 1 expression in calcium-dependent and calcineurin- and protein kinase A-dependent manner. ${ }^{13}$ The present study showed that TRPV1 activation by capsaicin could rescue the impaired autophagy in oxLDL-treated VSMCs. In WT-derived VSMCs, oxLDL-inhibited autophagy was significantly reversed by TRPV1 activation, and verified by increased LC3II/LC3I ratio, beclin-1 level and GFP-labeled autophagosomes in response to capsaicin treatment that was impeded by TRPV1 antagonist iRTX. However, in TRPV $1^{-1-}$-derived VSMCs, the capsaicin-induced autophagy amelioration was not shown. These data suggest that induction of autophagy might be another important mechanism of TRPV1 in regulating foam cell formation. For the first time, our study demonstrated that activation of TRPV 1 by capsaicin protected against foam cell formation by inducing autophagy in oxLDL-treated VSMCs.

We further investigated how autophagy is involved in the activation of TRPV1-regulated VSMC foam cell formation. As we know, autophagosomes fuse with lysosomes to form autolysosomes, and this is an essential step in autophagy that leads to degradation of their cargo. ${ }^{6} \mathrm{~A}$ recent study demonstrated that lipid droplets were delivered to lysosomes via autophagy, where lysosomal acid lipase acted to hydrolyze lipid droplet cholesterol esters to generate free cholesterol mainly for ABCA1-dependent efflux. ${ }^{10}$ Another study also showed that autophagy was involved in neutral cholesterol ester hydrolase-mediated degradation of cholesterol esters. ${ }^{11}$ In our study, capsaicin increased the level of LAMP-1, the marker protein of lysosomes, whereas TRPV1 antagonist iRTX abolished this effect, suggesting that the lysosome/ autophagolysosome pathway mediates the inhibition of TRPV1 on VSMC foam cell formation.

Foam cell formation is regulated by multiple mechanisms. Reportedly, change from the contractile to the synthetic 

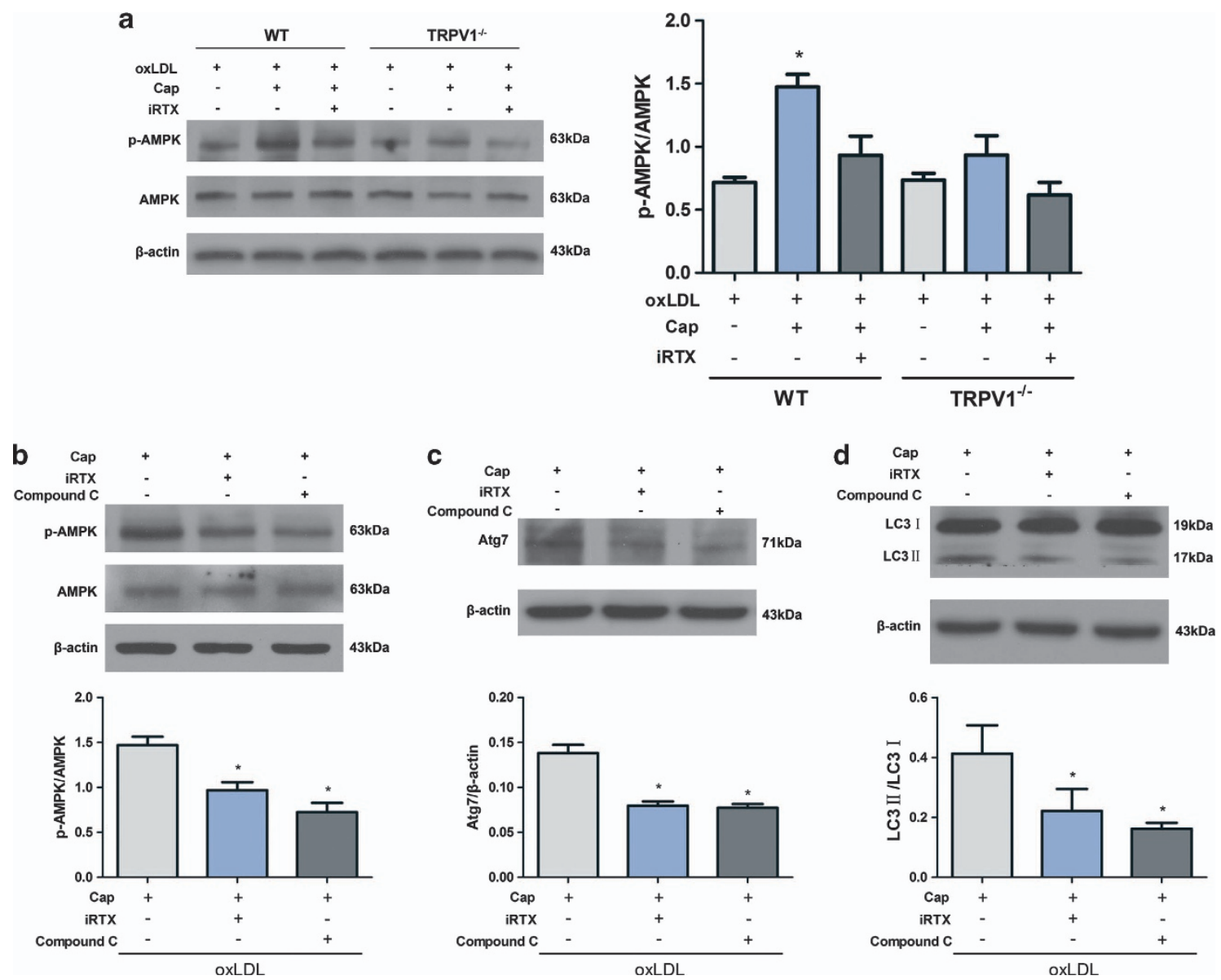

Figure 5 Activation of TRPV1 by capsaicin induces autophagy through AMPK signaling pathway. (a) Primary VSMCs from wild-type (WT) and TRPV1 ${ }^{-1-}$ mice were treated as indicated. Cap significantly increased p-AMPK (Thr-172) expression that was reversed by iRTX in VSMCs from WT mice. In contrast, Cap exerted no effect on the expression of $p$-AMPK in VSMCs from TRPV $1^{-1-}$ mice; ${ }^{*} P<0.05$ versus others. (b-d) Primary VSMCs from WT mice were treated with oxLDL and Cap in the absence or presence of $\mathrm{RTTX}$ or compound C. Compound C significantly inhibited the TRPV1-increased p-AMPK, Atg7 level and LC3-II/LC3-I ratio; ${ }^{*} P<0.05$ versus Cap alone. Results were presented as mean \pm S.D. (error bars) of three independent experiments

phenotype can accelerate the lipid accumulation in VSMCs. ${ }^{37}$ Herein, VSMCs in second to sixth passages were used in our study to ensure the contractile phenotype, manifested by high expression of $\alpha$-smooth muscle actin $(\alpha$-SMA) and low expression of osteopontin (OPN) (Supplementary Figure 2). Furthermore, capsaicin showed inhibitory effect on alteration of VSMCs from contractile to synthetic phenotype (Supplementary Figure 3). We therefore exclude the influence of alteration of VSMC phenotype on foam cell formation in the present study.

Next, we wondered which mechanism mediates the promotion of autophagy after TRPV1 activation. AMPK plays a key role in the regulation of protein and lipid metabolism, ${ }^{38}$ and can be activated by phosphorylating Thr-172 of its $\alpha$ subunit. ${ }^{39}$ AMPK activation was reported to be required for the induction of autophagy. ${ }^{40,41}$ In this study, activation of TRPV1 by capsaicin significantly increased p-AMPK (Thr-172) expression that was abolished by TRPV1 inhibitor iRTX in WT-derived VSMCs but not in TRPV $1^{-1}$-derived VSMCs. Moreover, compound C significantly inhibited the TRPV1activated AMPK and inhibited autophagy. These results suggest that activation of TRPV1 by capsaicin induces autophagy through activating AMPK signaling pathway. Regarding how the activation of TRPV1 activates AMPK signaling, we speculated it was through the increased cytosolic $\mathrm{Ca}^{2+}$. Reportedly, AMPK could be phosphorylated and activated by two upstream kinases: the tumor suppressor liver kinase B1 (LKB1) and $\mathrm{Ca}^{2+} /$ calmodulindependent protein kinase kinase- $\beta($ CaMKK $\beta) .{ }^{42-44}$ CaMKK $\beta$ mediates the activation of AMPK mainly in response to increased $\mathrm{Ca}^{2+}$, whereas LKB1 mediates activation primarily in response to energy stress. ${ }^{43-45}$ After phosphorylation, AMPK could activate the uncoordinated-51-like kinase 1 (ULK1) that combines with autophagy-related protein 1 (Atg1) to initiate the autophagic process including receiving signals of cellular nutrient status, recruiting downstream Atg proteins to the autophagosome formation site and governing autophagosome formation. ${ }^{46}$ TRPV1 is a wellknown cation channel, the activation of which can increase cytosolic $\mathrm{Ca}^{2+}$ significantly. ${ }^{13,15}$ Therefore, we speculated that activation of TRPV1 by capsaicin induced a significant elevation in cytosolic $\mathrm{Ca}^{2+}$ and subsequent CaMKK $\beta$ activation that further activated the AMPK-ULK1-autophagy pathway. 


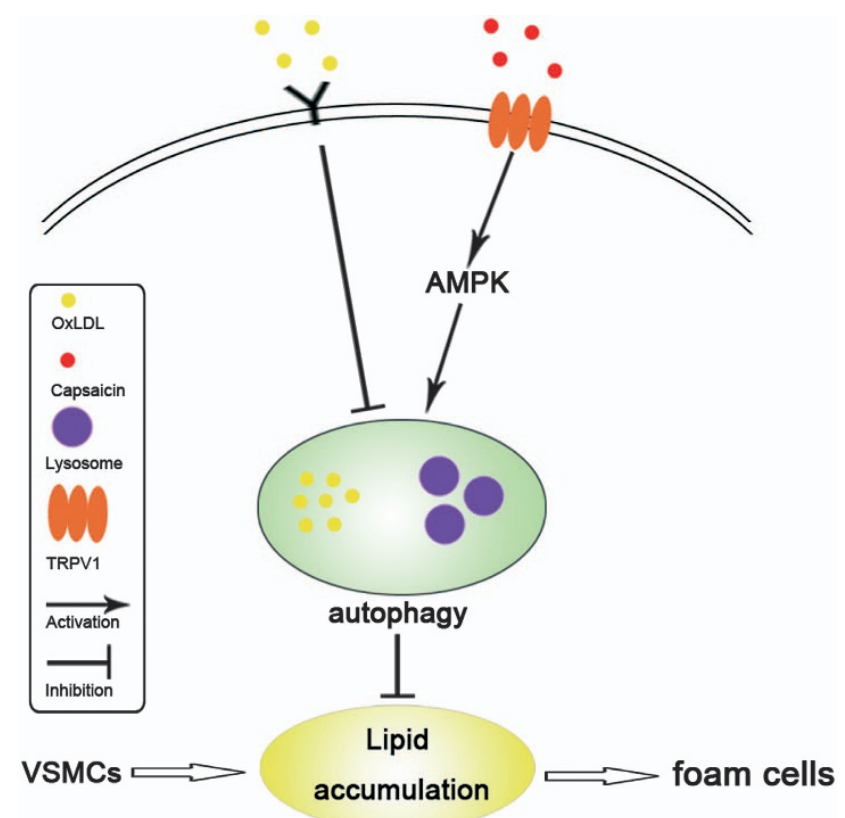

Figure 6 Schematic depiction of the autophagy in VSMC foam cell formation

Considering that oxLDL can lead to both autophagy and apoptosis concomitantly in atherosclerotic lesions, ${ }^{19,47}$ we also detected the apoptosis in oxLDL-loaded VSMCs. The results showed that $80 \mu \mathrm{g} / \mathrm{ml}$ oxLDL induced early apoptosis at a low level, but not late apoptosis and necrosis. This mild apoptotic-induction effect of oxLDL may be correlated to the moderate oxidation extent (22-25 nmol of MDA/mg protein). Reportedly, oxLDL with low oxidation extent was widely used to investigate lipid metabolism, whereas oxLDL with higher oxidation extent was required to induce apoptosis. ${ }^{19,48}$ It would be of interest to investigate the crosstalk between autophagy and apoptosis in oxLDL-loaded VSMCs in future.

There is a limitation that should be noted. Because of strong excitability, the dose of capsaicin used in vivo could not be as high as that used in vitro. The capsaicin plasma concentration of $0.01 \%$ oral capsaicin ( $\sim 33 \mathrm{nM}$, reportedly) is lower than the concentration used in vitro $(1 \mu \mathrm{M})$, and this may give rise to the possibility of different results between in vivo and in vitro studies regarding the mechanism we proposed, even though previous studies exhibited the same physiological effect between $0.01 \%$ of oral capsaicin in vivo and $1 \mu \mathrm{M}$ capsaicin in vitro. ${ }^{18,49}$ Further in vivo studies are needed to elucidate the above mechanisms.

In conclusion, the present study provided evidence that autophagy impeded VSMC foam cell formation induced by oxLDL; activation of TRPV1 by capsaicin rescued the autophagy impaired by oxLDL via activating AMPK signaling pathway, and ultimately inhibited the foam cell formation (Figure 6). Thus, our study provides novel pathological role of autophagy in VSMC foam cell formation and highlights TRPV1 as a promising therapeutic target in atherosclerosis.

\section{Materials and Methods}

Reagents. Dulbecco's modified Eagle's medium (DMEM) and fetal bovine serum (FBS) were purchased from Hycolon (Logan, UT, USA). Opti-MEM medium was from Gibco BRL (Carlsbad, CA, USA). Lipofectamine 2000 was from Invitrogen
(Carlsbad, CA, USA). Rap (10 nM), 3-MA (5 mM), iRTX (1 $\mu \mathrm{M})$, capsaicin and compound $\mathrm{C}(10 \mu \mathrm{M})$ were obtained from Sigma-Aldrich (St. Louis, MO, USA). GFPLC3-expressing plasmid (pEGFP-LC3) was from Cell Biolabs (San Diego, CA, USA). Annexin V-FITC Apoptosis Detection Kit was from Beyotime (Beijing, China). Caspase-Glo 3/7 kit was from Promega (Southampton, UK). Antibodies targeting Atg7 (1:1000), LAMP-1 (1:1000), $\beta$-actin $(1: 2000)$, OPN $(1: 1000)$, Atg7 siRNA (sc41448) and the scrambled siRNA (sc-37007) were from Santa Cruz Biotechnology (Santa Cruz, CA, USA). Antibody against LC3 $(2 \mu \mathrm{g} / \mathrm{ml})$ was from Novus Biologicals (Littleton, CO, USA). Antibody against beclin-1 $(1: 1000)$ was from Cell Signaling Technology (Beverly, MA, USA). Antibody targeting $\alpha$-SMA (1:1000) was from Abcam (Burlingame, CA, USA). The enhanced chemiluminescence (ECL) substrate was purchased from Pierce (San Diego, CA, USA).

Animals. The C57BL/6 J WT mice and TRPV1 ${ }^{-1-}$ mice were obtained at 8-10 weeks of age from Jackson Laboratory (Bar Harbor, Maine, USA). Both WT and TRPV $1^{-1-}$ mice were randomly divided into two groups $(n=6$ mice per group): high-fat diet (HFD) and high-fat diet plus $0.01 \%$ capsaicin for 16 weeks as previously described. ${ }^{13}$ Then, animals were killed for experiments. Animal care and procedures conformed with the Guide for the Care and Use of Laboratory Animals. Protocol approval was obtained from the Animal Research Committee of the Third Military Medical University.

Cell culture. VSMCs were isolated from the thoracic aorta of WT or TRPV1 ${ }^{-1-}$ mice using an explant technique using standard methods. ${ }^{50}$ Briefly, all the mice were killed by neck breaking and the aortic media was cut into $1 \times 1 \mathrm{~mm}$ pieces. The pieces were cultured in DMEM supplemented with $20 \%$ FBS, $100 \mathrm{U} / \mathrm{ml}$ penicillin and $100 \mathrm{mg} / \mathrm{ml}$ streptomycin in a humidified, $5 \% \quad \mathrm{CO}_{2} / 95 \%$ air atmosphere at $37^{\circ} \mathrm{C}$. When the cells formed a confluent monolayer (10 to 14 days), they were passaged by trypsinization. The cultured VSMCs were verified by using anti- $\alpha$-SMA antibody through immunocytochemical staining. To ensure maintenance of the contractile phenotype, we used cells in the second to sixth passages for experiments. Cells were incubated with serum-free medium for $24 \mathrm{~h}$ before all following experimental procedures.

Preparation of oxLDL. Human LDL was isolated from fresh human plasma by discontinuous density-gradient ultracentrifugation ${ }^{51}$ and was oxidized using $5 \mu \mathrm{M} \mathrm{Cu}_{2} \mathrm{SO}_{4}$ in PBS at $37^{\circ} \mathrm{C}$ for $20 \mathrm{~h}$. Oxidation was terminated by adding ethylenediaminetetraacetic acid, and the samples were dialyzed against phosphate buffer at $4^{\circ} \mathrm{C}$ for $24 \mathrm{~h}$. The extent of modification was determined by measuring thiobarbituric acid-reactive substances (TBARS). TBARS was determined colorimetrically using malondialdehyde (MDA) as standard. The TBARS of starting LDL is $0.10-0.15 \mathrm{nmol}$ of $\mathrm{MDA} / \mathrm{mg}$ protein and $0 \times \mathrm{LDL}$ is $22-25 \mathrm{nmol}$ of $\mathrm{MDA} / \mathrm{mg}$ protein.

Western blot analysis. Protein samples were obtained from homogenized cultured cells, and the protein concentration was determined. Protein samples were separated by SDS-PAGE, transferred to a PVDF membrane and blocked with TBS containing $0.05 \%$ Tween-20 (TBST) and $5 \%$ nonfat milk powder for $2 \mathrm{~h}$. The membranes were then incubated with appropriate primary antibodies overnight at $4^{\circ} \mathrm{C}$. After 4 washes with TBST, membranes were incubated with secondary antibodies for $2 \mathrm{~h}$ at room temperature. The proteins were detected by $\mathrm{ECL}$ and quantified using Labworks 4.6 (UVP, Upland, CA, USA). Western blot quantification was performed by densitometry and normalized to $\beta$-actin.

Apoptosis measurement. Apoptosis was determined by flow cytometry using the Annexin V-FITC Apoptosis Detection Kit according to the manufacturer's instructions. Briefly, primary VSMCs were grown in six-well plates. After different treatments, cells were trypsinized, harvested, washed twice with cold PBS and centrifuged at $1000 \times g$ for $5 \mathrm{~min}$. Cells were resuspended in $195 \mu \mathrm{l}$ binding buffer at a concentration of $1 \times 10^{6}$ cells per ml. Then, $5 \mu$ l of Annexin V-FITC was added. Cells were gently vortexed and incubated for $10 \mathrm{~min}$ in dark at room temperature. After the cells were centrifuged at $1000 \times g$ for $5 \mathrm{~min}, 190 \mu \mathrm{l}$ binding buffer and $5 \mu \mathrm{l}$ of PI were added. Samples were kept on ice and analyzed immediately by flow cytometry (Beckman Coulter, Miami, FL, USA). Normal live cells were represented as Annexin V-FITC negative and PI negative; early apoptotic cells as Annexin V-FITC positive and PI negative; late apoptotic or necrotic cells as Annexin V-FITC positive and PI positive. Apoptosis was also quantified by measuring caspase 3 activation using Caspase-Glo 3/7 Assay on a microplate reader (BioTek, Winooski, VT, USA) reader reading luminometer. The luminescence reading is directly proportional to caspase 3 activity. 
Assay for foam cell formation. Foam cells were quantified by Oil Red $O$ staining and intracellular total cholesterol content. Cultured VSMCs were plated on cover slides in six-well plates and treated with noted reagents for $24 \mathrm{~h}$ in serumfree DMEM. After that, the cells were washed with phosphate-buffered saline (PBS), fixed with $4 \%$ paraformaldehyde and stained with Oil Red O. Foam cells were photographed under a microscope at $\times 400$ magnification. Intracellular tota cholesterol content was detected by enzymatic assay as previously described. ${ }^{52}$ Briefly, cells after oxLDL treatment were harvested into a centrifuge tube and washed with PBS three times. Isopropylalcohol $(100 \mu \mathrm{l})$ was added to each tube, and intracellular liquid was extracted by ultrasonication. These mixtures were centrifuged for $10 \mathrm{~min}$ at $1500 \times g$ for the phase separation. The supernatant was used to detect total cholesterol by enzymatic assay. Sediment was then lysed on ice for $30 \mathrm{~min}$ in $100 \mu \mathrm{l}$ lysis buffer. After centrifugation, supernatants were collected for determining total cellular protein levels by Bradford assay method. The results were then expressed in $\mu \mathrm{g}$ of cholesterol per $\mathrm{mg}$ of cellular protein.

Transfection of GFP-LC3 and siRNA. VSMCs were seeded on coverslips in 24-well plates overnight, and then $0.8 \mu \mathrm{g}$ plasmid/well GFP-LC3 expressing plasmids were transiently transfected into the cells using Lipofectamine 2000 overnight in Opti-MEM medium following the manufacturer's instructions. Before they were treated, VSMCs were maintained in DMEM, supplemented with $10 \%$ FBS. Coverslips were mounted on glass slides and all of the cellular images were obtained using a confocal microscope confocal microscope (Leica, Wetzlar, Germany). For quantification of autophagic cells, GFP-LC3 punctated dots were determined from triplicates by counting a total of $>60$ cells at the end of the treatment. The siRNA transfection was performed using Lipofectamine 2000 according to the manufacturer's protocol. Briefly, the cells were plated in $500 \mu \mathrm{l}$ growth medium without antibiotics in 24-well plates. After cells reached $40-50 \%$ confluence, a 20-pmol sample of the siRNA oligomer was diluted in $50 \mu \mathrm{l}$ Opti-MEM; $1 \mu$ l Lipofectamine 2000 was diluted in $50 \mu$ l Opti-MEM. The solutions were mixed gently and incubated for $5 \mathrm{~min}$ at room temperature. After the 5 -min incubation, the diluted oligomer was combined with the diluted Lipofectamine 2000 , and the solution was mixed gently and incubated for $20 \mathrm{~min}$ at room temperature. The Oligomer-Lipofectamine 2000 complexes were then added to each well. After $6 \mathrm{~h}$ of transfection, DMEM complete medium was added. Cells were cultured in complete medium for $24 \mathrm{~h}$ before further analysis. Silencing efficiency was measured by western blot analysis. The scrambled siRNA was used as negative control (con siRNA).

Immunofluorescence. Serial fresh frozen sections of aorta and cultured VSMCs were fixed with $4 \%$ paraformaldehyde. Nonspecific proteins were blocked with $1 \%$ bovine serum albumin. After blocking, the sections were then incubated with primary antibody or anti- $\alpha$-SMA overnight at $4^{\circ} \mathrm{C}$. TRITC-labeled and FITClabeled secondary antibodies were then added for $1 \mathrm{~h}$ at $37^{\circ} \mathrm{C}$. Tissue sections or cells were then incubated with $10 \mathrm{mg} / \mathrm{ml}$ 40-6-diamidino-2-phenylindole (DAPI; Serva, Heidelberg, Germany) for $5 \mathrm{~min}$ at room temperature and analyzed using a confocal microscope (Leica).

Statistical analysis. Data are presented as means \pm S.D. of at least three independent experiments. Two-group comparison was performed using $t$-test for independent samples. Multiple-group statistical analyses were performed by oneway ANOVA with Bonferroni's multiple comparison post hoc test. Statistics were calculated with the GraphPad Prism 5 software package (La Jolla, CA, USA). The significance level was defined as $P<0.05$.

\section{Conflict of Interest}

The authors declare no conflict of interest.

Acknowledgements. This study was supported by grants from the National Natural Science Foundation of China (81271282) and the Natural Science Foundation Project of CQ CSTC (CSTC2012JJJQ10003).

1. Faggiotto $A$, Ross $R$, Harker $L$. Studies of hypercholesterolemia in the nonhuman primate. I. Changes that lead to fatty streak formation. Arteriosclerosis 1984; 4: 323-340.

2. Glukhova MA, Ornatsky OI, Frid MG, Kabakov AE, Adany RR, Muszbek L et al. Identification of smooth muscle-derived foam cells in the atherosclerotic plaque of human aorta with monoclonal antibody IIG10. Tissue Cell 1987; 19: 657-663.
3. Vollmer E, Roessner A, Bosse A, Bocker W, Kaesberg B, Robenek $\mathrm{H}$ et al. Immunohistochemical double labeling of macrophages, smooth muscle cells, and apolipoprotein E in the atherosclerotic plaque. Pathol Res Pract 1991; 187: 184-188.

4. Rosenfeld ME, Ross R. Macrophage and smooth muscle cell proliferation in atherosclerotic lesions of WHHL and comparably hypercholesterolemic fat-fed rabbits. Arteriosclerosis 1990; 10: 680-687.

5. Levine B, Kroemer G. Autophagy in the pathogenesis of disease. Cell 2008; 132: 27-42.

6. Mizushima N, Levine B, Cuervo AM, Klionsky DJ. Autophagy fights disease through cellular self-digestion. Nature 2008; 451: 1069-1075.

7. Kovsan J, Bashan N, Greenberg AS, Rudich A. Potential role of autophagy in modulation of lipid metabolism. Am J Physiol Endocrinol Metab 2010; 298: E1-E7.

8. Singh R, Kaushik S, Wang Y, Xiang Y, Novak I, Komatsu M et al. Autophagy regulates lipid metabolism. Nature 2009; 458: 1131-1135.

9. Zhang Y, Goldman S, Baerga R, Zhao Y, Komatsu M, Jin S. Adipose-specific deletion of autophagy-related gene 7 (atg7) in mice reveals a role in adipogenesis. Proc Natl Acad Sci USA 2009; 106: 19860-19865.

10. Ouimet M, Franklin V, Mak E, Liao X, Tabas I, Marcel YL. Autophagy regulates cholesterol efflux from macrophage foam cells via lysosomal acid lipase. Cell Metab 2011; 13: 655-667.

11. Mei S, Gu H, Ward A, Yang X, Guo H, He K et al. p38 mitogen-activated protein kinase (MAPK) promotes cholesterol ester accumulation in macrophages through inhibition of macroautophagy. J Biol Chem 2012; 287: 11761-11768.

12. Farfariello V, Amantini C, Santoni G. Transient receptor potential vanilloid 1 activation induces autophagy in thymocytes through ROS-regulated AMPK and Atg4C pathways. $J$ Leukoc Biol 2012; 92: 421-431.

13. Ma L, Zhong J, Zhao Z, Luo Z, Ma S, Sun J et al. Activation of TRPV1 reduces vascular lipid accumulation and attenuates atherosclerosis. Cardiovasc Res 2011; 92: 504-513.

14. Vriens J, Appendino G, Nilius B. Pharmacology of vanilloid transient receptor potential cation channels. Mol Pharmacol 2009; 75: 1262-1279.

15. Zhang LL, Yan Liu D, Ma LQ, Luo ZD, Cao TB, Zhong J et al. Activation of transient receptor potential vanilloid type-1 channel prevents adipogenesis and obesity. Circ Res 2007; 100: 1063-1070.

16. Xu X, Wang $\mathrm{P}, \mathrm{Zhao} \mathrm{Z}$, Cao T, He H, Luo Z et al. Activation of transient receptor potential vanilloid 1 by dietary capsaicin delays the onset of stroke in stroke-prone spontaneously hypertensive rats. Stroke 2011; 42: 3245-3251.

17. Zhao JF, Ching LC, Kou YR, Lin SJ, Wei J, Shyue SK et al. Activation of TRPV1 prevents OxLDL-induced lipid accumulation and TNF-alpha-induced inflammation in macrophages: role of liver X receptor alpha. Mediators Inflamm 2013; 2013: 925171.

18. Li Q, Li L, Wang F, Chen J, Zhao Y, Wang P et al. Dietary capsaicin prevents nonalcoholic fatty liver disease through transient receptor potential vanilloid 1-mediated peroxisome proliferator-activated receptor delta activation. Pflugers Arch 2013; 465: 1303-1316.

19. Ding Z, Wang X, Schnackenberg L, Khaidakov M, Liu S, Singla S et al. Regulation of autophagy and apoptosis in response to OX-LDL in vascular smooth muscle cells, and the modulatory effects of the microRNA hsa-let-7 g. Int J Cardiol 2013; 168: 1378-1385.

20. Oh SH, Kim YS, Lim SC, Hou YF, Chang IY, You HJ. Dihydrocapsaicin (DHC), a saturated structural analog of capsaicin, induces autophagy in human cancer cells in a catalaseregulated manner. Autophagy 2008; 4: 1009-1019.

21. Raines EW, Ross R. Smooth muscle cells and the pathogenesis of the lesions of atherosclerosis. Br Heart J 1993; 69(1 Suppl): S30-S37.

22. Levine B, Klionsky DJ. Development by self-digestion: molecular mechanisms and biological functions of autophagy. Dev Cell 2004; 6: 463-477.

23. Terman A, Gustafsson B, Brunk UT. Autophagy, organelles and ageing. J Pathol 2007; 211: 134-143.

24. Cecconi F, Levine B. The role of autophagy in mammalian development: cell makeover rather than cell death. Dev Cell 2008; 15: 344-357

25. Notte A, Ninane N, Arnould T, Michiels C. Hypoxia counteracts taxol-induced apoptosis in MDA-MB-231 breast cancer cells: role of autophagy and JNK activation. Cell Death Dis 2013; 4: e638.

26. Alvarez-Erviti L, Seow Y, Schapira AH, Rodriguez-Oroz MC, Obeso JA, Cooper JM. Influence of microRNA deregulation on chaperone-mediated autophagy and alphasynuclein pathology in Parkinson's disease. Cell Death Dis 2013; 4: e545.

27. Rioux JD, Xavier RJ, Taylor KD, Silverberg MS, Goyette P, Huett A et al. Genome-wide association study identifies new susceptibility loci for Crohn disease and implicates autophagy in disease pathogenesis. Nat Genet 2007; 39: 596-604.

28. Martinet W, De Meyer GR. Autophagy in atherosclerosis. Current Atheroscler Rep 2008; 10: $216-223$.

29. Martinet W, De Meyer GR. Autophagy in atherosclerosis: a cell survival and death phenomenon with therapeutic potential. Circ Res 2009; 104: 304-317.

30. Yamada Y, Doi T, Hamakubo T, Kodama T. Scavenger receptor family proteins: roles for atherosclerosis, host defence and disorders of the central nervous system. Cell Mol Life Sci 1998; 54: 628-640.

31. Luo DX, Xia CL, Li JM, Xiong Y, Yuan HY, Tang ZW et al. Static pressure accelerates oxLDL-induced cholesterol accumulation via SREBP-1-mediated caveolin-1 downregulation in cultured vascular smooth muscle cells. Biochem Biophys Res Commun 2010; 403: 52-58.

32. Neufeld TP. TOR-dependent control of autophagy: biting the hand that feeds. Curr Opin Cell Biol 2010; 22: 157-168. 
33. Brito PM, Devillard R, Negre-Salvayre A, Almeida LM, Dinis TC, Salvayre R et al Resveratrol inhibits the mTOR mitogenic signaling evoked by oxidized LDL in smooth muscle cells. Atherosclerosis 2009; 205: 126-134.

34. Recchia AG, Musti AM, Lanzino M, Panno ML, Turano E, Zumpano R et al. A cross-talk between the androgen receptor and the epidermal growth factor receptor leads to p38MAPK-dependent activation of mTOR and cyclinD1 expression in prostate and lung cancer cells. Int J Biochem Cell Bioly 2009; 41: 603-614.

35. Caterina MJ, Schumacher MA, Tominaga M, Rosen TA, Levine JD, Julius D. The capsaicin receptor: a heat-activated ion channel in the pain pathway. Nature 1997; 389: 816-824.

36. O'Neil RG, Brown RC. The vanilloid receptor family of calcium-permeable channels: molecular integrators of microenvironmental stimuli. News Physiol Sci 2003; 18: 226-231.

37. Weinert S, Poitz DM, Auffermann-Gretzinger S, Eger L, Herold J, Medunjanin S et al. The lysosomal transfer of LDL/cholesterol from macrophages into vascular smooth muscle cells induces their phenotypic alteration. Cardiovasc Res 2013; 97: 544-552.

38. Hardie DG. Adenosine monophosphate-activated protein kinase: a central regulator of metabolism with roles in diabetes, cancer, and viral infection. Cold Spring Harb Symp Quant Biol 2011; 76: 155-164.

39. Hawley SA, Pan DA, Mustard KJ, Ross L, Bain J, Edelman AM et al. Calmodulindependent protein kinase kinase-beta is an alternative upstream kinase for AMP-activated protein kinase. Cell Metab 2005; 2: 9-19.

40. Meley D, Bauvy C, Houben-Weerts JH, Dubbelhuis PF, Helmond MT, Codogno P et al. AMP-activated protein kinase and the regulation of autophagic proteolysis. J Biol Chem 2006; 281: 34870-34879.

41. Dando I, Donadelli M, Costanzo C, Dalla Pozza E, D’Alessandro A, Zolla L et al. Cannabinoids inhibit energetic metabolism and induce AMPK-dependent autophagy in pancreatic cancer cells. Cell Death Dis 2013; 4: e664.

42. Hurley RL, Anderson KA, Franzone JM, Kemp BE, Means AR, Witters LA. The Ca2 + I calmodulin-dependent protein kinase kinases are AMP-activated protein kinase kinases. J Biol Chem 2005; 280: 29060-29066

43. Woods A, Dickerson K, Heath R, Hong SP, Momcilovic M, Johnstone SR et al. Ca2 + I calmodulin-dependent protein kinase kinase-beta acts upstream of AMP-activated protein kinase in mammalian cells. Cell Metab 2005; 2: 21-33.

44. Shaw RJ, Kosmatka M, Bardeesy N, Hurley RL, Witters LA, DePinho RA et al. The tumor suppressor LKB1 kinase directly activates AMP-activated kinase and regulates apoptosis in response to energy stress. Proc Natl Acad Sci USA 2004; 101: 3329-3335.
45. Hoyer-Hansen M, Bastholm L, Szyniarowski P, Campanella M, Szabadkai G, Farkas T et al. Control of macroautophagy by calcium, calmodulin-dependent kinase kinase-beta, and Bcl-2. Mol Cell 2007; 25: 193-205.

46. Mizushima N. The role of the Atg1/ULK1 complex in autophagy regulation. Curr Opin Cell Biol 2010; 22: 132-139.

47. Chen J, Mehta JL, Haider N, Zhang X, Narula J, Li D. Role of caspases in Ox-LDL-induced apoptotic cascade in human coronary artery endothelial cells. Circ Res 2004; 94: 370-376.

48. Lee T, Chau L. Fas/Fas ligand-mediated death pathway is involved in oxLDL-induced apoptosis in vascular smooth muscle cells. Am J Physiol Cell Physiol 2001; 280: C709-C718.

49. Yang D, Luo Z, Ma S, Wong WT, Ma L, Zhong J et al. Activation of TRPV1 by dietary capsaicin improves endothelium-dependent vasorelaxation and prevents hypertension. Cell Metab 2010; 12: 130-141.

50. McMurray HF, Parrott DP, Bowyer DE. A standardised method of culturing aortic explants, suitable for the study of factors affecting the phenotypic modulation, migration and proliferation of aortic smooth muscle cells. Atherosclerosis 1991; 86: 227-237.

51. de Bem AF, Farina M, Portella Rde L, Nogueira CW, Dinis TC, Laranjinha JA et al. Diphenyl diselenide, a simple glutathione peroxidase mimetic, inhibits human LDL oxidation in vitro. Atherosclerosis 2008; 201: 92-100.

52. Xue JH, Yuan Z, Wu Y, Liu Y, Zhao Y, Zhang WP et al. High glucose promotes intracellular lipid accumulation in vascular smooth muscle cells by impairing cholesterol influx and efflux balance. Cardiovasc Res 2010; 86: 141-150.

(c) (1) $(-)$ Cell Death and Disease is an open-access journal published by Nature Publishing Group. This work is licensed under a Creative Commons Attribution-NonCommercialNoDerivs 3.0 Unported License. The images or other third party material in this article are included in the article's Creative Commons license, unless indicated otherwise in the credit line; if the material is not included under the Creative Commons license, users will need to obtain permission from the license holder to reproduce the material. To view a copy of this license, visit http://creativecommons.org/licenses/ by-nc-nd/3.0/

Supplementary Information accompanies this paper on Cell Death and Disease website (http://www.nature.com/cddis) 